\title{
PEDICLED PERICARDIUM FOR REPAIR OF RIGHT VENTRICULAR OUTFLOW TRACT AND PULMONARY ARTERIAL STENOSES IN TETRALOGY OF FALLOT: A SIX-YEAR EXPERIENCE
}

Wassim Khoury, MD

Loïc Lang-Lazdunski, MD

Françoise Vernant, MD

Michèle Thibert, MD

Francine Leca, MD
From June 1988 through June 1994, 20 children with symptomatic tetralogy of Fallot, associated with hypoplastic or stenotic pulmonary arteries in 19 cases, were operated on in our institution. Mean age at operation was $49.5 \pm 43$ months (ranging from 10 months to 12.5 years). Mean weight was $13.5 \pm 6.5 \mathrm{~kg}$ (range 6.2 to $30 \mathrm{~kg}$ ) and mean body surface area was $0.6 \pm 0.2 \mathrm{~m}^{2}$. Mean preoperative hematocrit value was $47.6 \% \pm 11.1 \%$, and mean preoperative arterial oxygen saturation ratio was $75.7 \pm 9.5$. Six patients $(30 \%)$ had prior systemic-pulmonary arterial shunts. Pulmonary arterial stenoses were congenital or iatrogenic (or both) and were located principally on the left pulmonary artery $(63 \%)$, on the pulmonary bifurcation $(15 \%)$, or separately on the left and right pulmonary arteries $(21 \%)$. In all children the puImonary arterial tree was repaired with the patient's own pedicled pericardium. Mean follow-up is $36 \pm 25.2$ months (range 1 to 71 months). Hospital mortality rate was $0 \%$. There was one late death, and two children were lost to long-term follow-up. No child required reoperation. Seventeen children returned for evaluation, consisting of physical examination, electrocardiogram, chest roentgenogram, and Doppler echocardiogram, and 11 underwent late catheterization or magnetic resonance imaging of the chest to evaluate the pulmonary arterial repair. All children were in New York Heart Association class I or II. Right ventricular function was normal by echocardiography in $100 \%$ with a mean right ventricular systolic pressure of $39.37 \pm 8.4 \mathrm{~mm} \mathrm{Hg}$. Mild to moderate pulmonary regurgitation was present in the majority of patients. The results of pulmonary arterial repair were good in $100 \%$. There was no residual stenosis, and we observed uniform enlargement of the repaired pulmonary arteries over a 5-month to 6-year follow-up period. These results are of particular interest inasmuch as other materials previously used for repair of pulmonary arteries do not grow and may even shrink, resulting in residual stenosis. (J Thorac Cardiovasc Surg 1996;112:424-32)
Size and configuration of the pulmonary arteries Shave been thought to be important determinants of postoperative right ventricular function after complete repair of tetralogy of Fallot (TOF). As such, they may affect the result of repair when the pulmonary arteries are hypoplastic or stenotic. ${ }^{1-4}$

From the Department of Thoracic and Cardiovascular Surgery, Hôpital Laënnec, Paris, France.

Received for publication July 28, 1995; revisions requested Sept. 13, 1995; revisions received Jan. 17, 1996; accepted for publication Jan. 23, 1996.

Address for reprints: Loïc Lang-Lazdunski, MD, Service de Chirurgie Thoracique et Cardiovasculaire, Hôpital Laënnec, 42 rue de Sèvres, 75007 Paris, France.

Copyright (c) 1996 by Mosby-Year Book, Inc.

$0022-5223 / 96 \$ 5.00+0 \quad \mathbf{1 2 / 1 / 7 2 1 2 6}$
Numerous techniques and materials, such as autologous pericardium, Dacron polyester, polytetrafluoroethylene, and others, have been used to repair such pulmonary arteries, often with unsatisfactory results. ${ }^{3,5-7}$ In 1984, Guyton and colleagues ${ }^{8}$ demonstrated the growth potential of broadly based autologous pericardial flaps and postulated that this material should be suitable for repair of small pulmonary arteries. In 1988 Hvass and colleagues ${ }^{9}$ reported their successful use of pericardial flaps for reconstruction of hypoplastic pulmonary arterial branches.

In 1988 we started to use this material for repair of hypoplastic or stenotic pulmonary arteries in children with symptomatic TOF. This study reports our experience in 20 children operated on in Laënnec Hospital from June 1988 through June 1994. 
Table I. Preoperative status of pulmonary arteries

\begin{tabular}{|c|c|c|c|c|c|c|}
\hline $\begin{array}{c}\text { Patient } \\
\text { no. }\end{array}$ & $\begin{array}{l}\text { Pulmonary } \\
\text { anulus }\end{array}$ & $\begin{array}{c}\text { Pulmonary } \\
\text { trunk }\end{array}$ & Bifurcation & $L P A$ & $R P A$ & $\begin{array}{l}\text { Previous } \\
\text { operation }\end{array}$ \\
\hline 1 & & Dilated & & + Or & & \\
\hline 2 & + & + & + & + Or & & MBTS left \\
\hline 3 & + & + & & & & \\
\hline 4 & + & + & & + Or & & MBTS left \\
\hline 5 & + & + & & & & \\
\hline 6 & + & + & & $+\mathrm{Or} / \mathrm{B}$ & & MBTS left \\
\hline 7 & + & + & & $+\mathrm{Or}$ & & \\
\hline 8 & + & + & & $+\mathrm{Or}$ & & \\
\hline 9 & + & + & & + Or & & \\
\hline 10 & + & + & & & & \\
\hline 11 & + & + & & + Or & + Or & \\
\hline 12 & + & + & & $+\mathrm{Or}$ & & \\
\hline 13 & + & + & + & $+\mathrm{Or}$ & $\pm \mathrm{Or}$ & \\
\hline 14 & + & + & & Or & & MBTS right \\
\hline 15 & & + & & $+\mathrm{Or}$ & $\pm \mathrm{Or}$ & \\
\hline 16 & + & + & & $+\mathrm{Or}$ & $\pm \mathrm{Hyp}$ & \\
\hline 17 & + & + & & $+B$ & & MBTS left \\
\hline \multicolumn{7}{|l|}{18} \\
\hline 19 & + & + & \pm & $+\mathrm{B}$ & & MBTS left \\
\hline 20 & + & + & & + & & \\
\hline \multirow[t]{2}{*}{ Total } & $17+$ & $18+$ & $2+$ & $16+$ & $1+$ & \\
\hline & & & $1 \pm$ & & $3 \pm$ & \\
\hline
\end{tabular}

LPA, Left pulmonary artery; $R P A$, right pulmonary artery; $M B T S$, modified Blalock-Taussig shunt; $O r$, origin; $B$, Blalock; + , stenosis; \pm , mild stenosis.

\section{Patients and methods}

From June 1988 through June 1994, 539 patients with TOF were operated on in our institution. During the same period 20 children with symptomatic TOF, 19 of whom had various pulmonary arterial stenoses, underwent repair of the right ventricular outflow tract (RVOT), pulmonary trunk, or branches with the use of autologous pericardial flaps. The patients comprised 11 boys and nine girls, their ages ranging from 10 months to 12.5 years (mean $49.5 \pm$ 43 months). Seven patients were younger than 2 years of age. The children weighed 6.2 to $30 \mathrm{~kg}$ (mean $13.5 \pm 6.5$ $\mathrm{kg}$ ). The mean body surface area was $0.59 \pm 0.20 \mathrm{~m}^{2}$, ranging from 0.33 to $1.05 \mathrm{~m}^{2}$.

The mean preoperative hematocrit value was $47.6 \% \pm$ $11.1 \%$ and the mean arterial oxygen saturation ratio was $75.7 \pm 9.5$. All children had signs and symptoms of inadequate pulmonary blood flow, including persistent $(55 \%)$ or intermittent $(45 \%)$ cyanosis, decreased exercise tolerance, and hypoxic spells (20\%). Six systemic-pulmonary arterial shunts had previously been performed on six patients (five modified Blalock-Taussig shunts on the left side and one on the right side). The 20 children also had various associated cardiovascular anomalies, such as a right aortic arch $(n=4)$, an atrial septal defect $(n=2)$, multiple ventricular septal defects $(n=1)$, an anomalous left anterior descending coronary artery originating from the right coronary artery $(n=1)$, a left superior vena cava $(n=1)$, and an anomalous mitral valve $(n=1)$.

All patients had preoperative evaluation by two-dimensional echocardiography to assess the size, stenosis, or hypoplasia of the pulmonary trunk and branches. All patients but four underwent preoperative catheterization. One boy did not have catheterization because of ongoing endocarditis. One other boy underwent preoperative magnetic resonance imaging (MRI) of the chest. The last two children had echocardiographic studies, and good visualization of the left and right pulmonary arteries was obtained.

The internal diameters of the pulmonary arteries were measured at their origins, at the level of the prebranching point, and at the level of the stenoses. Locations of the stenoses on the pulmonary arterial tree are described in Table I.

Surgical technique. All children were operated on by two of us (F.L. and W.K.). All procedures were performed via a median sternotomy with mild hypothermic cardiopulmonary bypass instituted through an ascending aortic cannula and two venous cannulas. After aortic crossclamping the myocardium was protected with cold oxygenated blood cardioplegic solution infused into the aortic root every 20 minutes, as well as by topical cooling.

The broadly based pericardial flaps were tailored before cardiopulmonary bypass began. The pericardial sac was usually opened transversely in the midline near the diaphragm. The incision was extended along the diaphragm toward both phrenic nerves and then went cephalad, parallelling the right phrenic nerve closely, until the flap could be rotated in front of the pulmonary arterial segment we wished to repair. The pericardium usually remained normally attached on the left side (Fig. 1).

Operative repair was as follows: The ductus arteriosus and surgical shunts (six patients) were ligated immediately after the institution of bypass. Atrial septal defects were closed. A moderate resection of infundibular muscle bands was done through a limited longitudinal right ventriculotomy. The ventricular septal defect was closed 


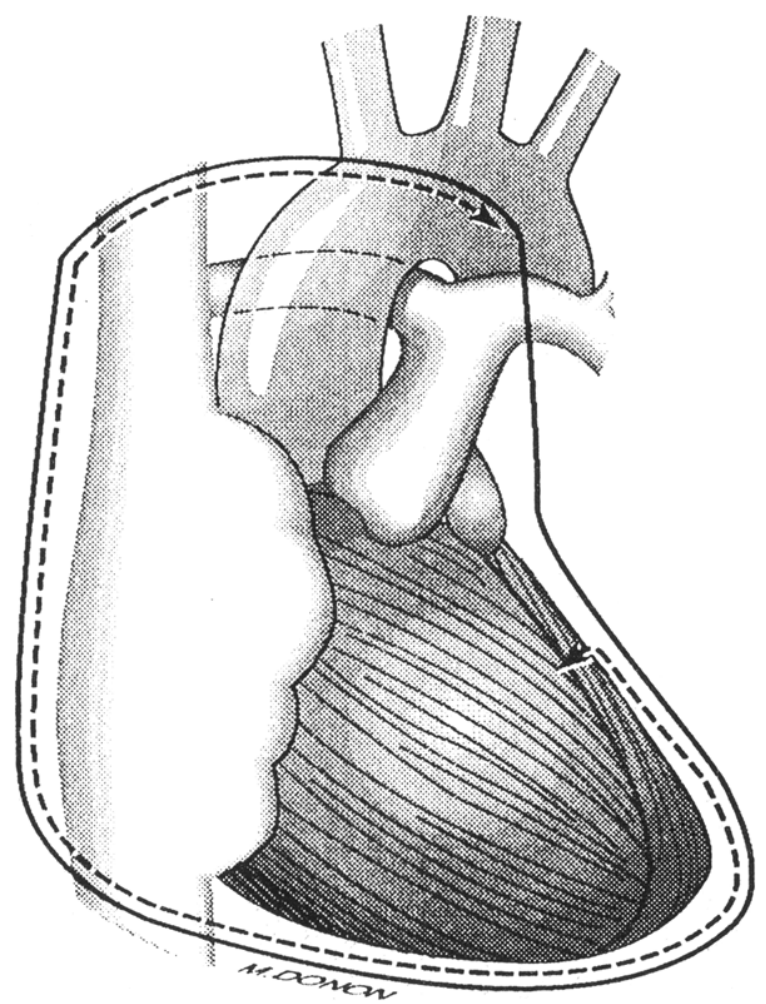

Fig. 1. Preparation and tailoring of the pericardial flap. Arrows indicate the line of pericardial incision. The pericardial flap remains broadly based on the left side of the pericardium with the left phrenic nerve along its base.

through the ventriculotomy with a Dacron patch (Meadox Medicals, Inc., Oakland, N.J.) or a bovine pericardial patch (Peri-Guard Pericardium, Bio-Vascular, Inc., St. Paul, Minn.) by means of interrupted pledget-supported sutures or continuous sutures. If the pulmonary valve anulus was hypoplastic, the infundibulotomy incision was extended across the anulus between the valve commissures as far as needed (up to the bifurcation or up to the left or right pulmonary artery). The size of the pulmonary trunk and of the left and right pulmonary arteries was measured by Hegar probes, and then those arteries were calibrated to fit a normal diameter, adjusted to the child's body surface area. ${ }^{10}$ Infundibular stenosis that could not be relieved by simple resection was treated with an oval patch, the base of which was sutured to the pulmonary ring. Hypoplasia of the anulus and trunk with a good bifurcation and stenosis of the left branch was treated with a transannular patch extending to the left branch across the stenosis, to guarantee good ramification of the right branch and to reduce the risk of residual stenosis of the distal trunk. The stenosis of the bifurcation or of the right and left branches was repaired with a Y-shaped patch. All sutures used on the pulmonary arteries were continuous 6-0 or 7-0 absorbable sutures.

A transannular RVOT repair was required in 18 patients $(90 \%)$. An infundibular pedicled pericardial flap
Table II. Type of repair with pericardial flaps

\begin{tabular}{|c|c|c|c|c|c|c|}
\hline $\begin{array}{c}\text { Patient } \\
\text { no. }\end{array}$ & Infundibulum & Anulus & Trunk & Bifurcation & $L P A$ & $R P A$ \\
\hline 1 & & & & & + & \\
\hline 2 & + & + & + & & + & \\
\hline 3 & + & $+(\mathrm{M})$ & + & & & \\
\hline 4 & & + & + & & + & \\
\hline 5 & $+($ tube $)$ & + & + & & & \\
\hline 6 & + & + & + & & + & \\
\hline 7 & + & + & + & & + & \\
\hline 8 & + & + & + & & + & \\
\hline 9 & + & $+(\mathrm{M})$ & & & & \\
\hline 10 & + & + & + & & & \\
\hline 11 & & + & + & + & + & + \\
\hline 12 & & + & + & & + & \\
\hline 13 & + & $+(\mathrm{M})$ & + & + & + & \\
\hline 14 & & + & + & & + & \\
\hline 15 & & + & + & & + & \\
\hline 16 & + & $+(M)$ & & & & \\
\hline 17 & & + & + & & + & \\
\hline 18 & + & & & & & \\
\hline 19 & + & $+(\mathrm{M})$ & & & & \\
\hline 20 & + & + & + & & + & \\
\hline
\end{tabular}

$M$, Monocusp pulmonary valve; + , site of repair.

alone was used in an $81 / 2$-year-old boy with ongoing endocarditis, and a double repair (bovine pericardial patch on the infundibulum plus pedicled pericardial flap on the left pulmonary artery) was used in a $11 / 2$-year-old girl. A pedicled pericardial flap was tailored as a tube to reconstruct a new pulmonary arterial trunk in a 56-monthold girl with an anomalous left anterior descending coronary artery originating from the right coronary artery. In addition, five children underwent insertion of a pulmonary monocusp valve before the RVOT was repaired. (The monocusp valve was tailored from pericardium sutured to the underside of the pericardial flap). In nine children $(45 \%)$ the infundibulum was enlarged with a preserved bovine pericardial patch tailored to the normal size. In addition, bovine pericardium was used in three patients $(15 \%)$ to repair in part the pulmonary trunk or the left pulmonary artery. In all patients, a pedicled pericardial flap was used to repair partly or totally the pulmonary outflow tract and the branches (Table II).

The cardiopulmonary bypass time ranged from 105 to 205 minutes (mean $134 \pm 24.8$ minutes) and the aortic crossclamp time ranged from 40 to 145 minutes (mean $83 \pm 24.4$ minutes). Pressures in the right and left ventricles and in the main pulmonary artery were measured before the chest was closed. Right ventricular/left ventricular pressure ratios were measured and ranged between $30 \%$ and $60 \%$ in all children. Left and right atrial catheters were placed in all children.

Follow-up. The immediate postoperative study included clinical status, hemodynamic and oximetric studies, chest x-ray studies, use of positive inotropic drugs, and duration of ventilatory support. All patients had repeated roentgenographic, electrocardiographic, and echocardiographic studies before they were discharged. Follow-up information was obtained between 1 and 71 months after 
Volume 112, Number 2

Table III. Pulmonary arteries: Preoperative values and postoperative follow-up

\begin{tabular}{ccccc}
$\begin{array}{c}\text { No./sex/age } \\
(\mathrm{mo})\end{array}$ & $\begin{array}{c}\text { BSA } \\
\left(\mathrm{m}^{2}\right)\end{array}$ & $\begin{array}{c}\text { Preop. PA index } \\
\left(\mathrm{mm}^{2} / \mathrm{BS} \text { A }\right)\end{array}$ & $\begin{array}{c}\text { Postop. Pa index } \\
\left(\mathrm{mm}^{2} / \mathrm{BS} \text { A }\right)\end{array}$ & $\begin{array}{c}\text { Residual } \\
\text { stenosis }\end{array}$ \\
\hline $1 / \mathrm{F} / 17$ & 0.42 & 413 & $307(\mathrm{MRI})$ & None \\
$2 / \mathrm{F} / 39$ & 0.56 & 182 & 195 & None \\
$3 / \mathrm{M} / 24$ & 0.48 & 327 & - & None \\
$4 / \mathrm{F} 30$ & 0.58 & 330 & 344 & None \\
$5 / \mathrm{F} / 56$ & 0.65 & 242 & $348(\mathrm{MRI})$ & None \\
$6 / \mathrm{M} / 41$ & 0.56 & $310(\mathrm{MRI})$ & 241 & None \\
$7 / \mathrm{M} / 47$ & 0.54 & 385 & 354 & None \\
$8 / \mathrm{M} / 130$ & 0.97 & 364 & - & None \\
$9 / \mathrm{M} / 21$ & 0.42 & 346 & - & None \\
$10 / \mathrm{M} / 12$ & 0.33 & 431 & - & None \\
$11 / \mathrm{F} / 87$ & 0.80 & 161 & $199(\mathrm{MRI})$ & None \\
$12 / \mathrm{F} / 11$ & 0.36 & 185 & 184 & None \\
$13 / \mathrm{F} / 48$ & 0.62 & 162 & 272 & None \\
$14 / \mathrm{F} / 21$ & 0.48 & 331 & - & None \\
$15 / \mathrm{M} / 12$ & 0.40 & 251 & - & None \\
$16 / \mathrm{F} / 11$ & 0.35 & 191 & - & None \\
$17 / \mathrm{M} / 151$ & 0.94 & 225 & - & None \\
$18 / \mathrm{M} / 101$ & 0.80 & No cath. & - & None \\
$19 / \mathrm{M} / 120$ & 1.05 & 183 & & None
\end{tabular}

$B S A$, Body surface area; $P A$, pulmonary artery; cath., catheterization.

the operation by direct family contact and through correspondence with the referring cardiologist. A chest roentgenogram, an electrocardiogram, and an echocardiogram were obtained in $100 \%$ of patients.

Chest MRI and catheterization were performed only in children living in France. MRI examinations and pulmonary angiograms were impossible to obtain for children living in Mayotte Island or in Africa because of economic and political problems. Seven children had late recatheterization. Chest MRI studies were performed in four patients. Two children living outside of France, in Mayotte Island, were lost to late follow-up after they were discharged from our institution. However, some information, such as clinical status, electrocardiograms, chest x-ray films, and echocardiograms obtained during the first postoperative year, were available (Table III).

Statistical analysis. The medical record of each child was reviewed to determine the morphologic, clinical, surgical, and follow-up data. Preoperative and postoperative echocardiograms, cineangiograms, MRIs, and hemodynamic data were reviewed with particular attention paid to the morphologic features of the initial lesion and the presence of postoperative residual lesions. Pulmonary artery indices were measured from preoperative and postoperative cineangiograms according to standard criteria. Standard methods were used to obtain means and standard errors.

\section{Results}

Mortality. There were no hospital deaths. One late death occurred in a 19-month-old boy ( 7 months after the operation). This child probably died of a cardiac rhythm disturbance resulting from severe bronchopneumonia. An autopsy revealed a relatively hypoplastic right branch, a moderate dilatation of the pericardial flap on the RVOT, and a hypertrophied right ventricle.

Follow-up. The mean stay in the intensive care unit was $3.4 \pm 1.4$ days for $90 \%$ of the children. The mean duration of ventilatory support was $30.5 \pm$ 21.1 hours for $90 \%$ of patients. Nine patients required dobutamine (mean dose $8 \mu \mathrm{g} / \mathrm{kg}$ per minute) for inotropic support during the first postoperative hours.

Complications. Postoperative complications included pneumonia in one, phrenic palsy in two (one on the right side and one on the left side), and bleeding necessitating reentry in two. One of the last two children had postoperative convulsions and left-sided hemiplegia, which totally regressed over a period of a few months.

Midterm results. Midterm follow-up status was ascertained for 18 of $20(90 \%)$ surgical survivors. Cumulative follow-up was 60 patient-years with a mean follow-up of $36 \pm 25.2$ months per patient (ranging from 1 to 71 months). No patient required a reoperation.

Of the 17 patients who returned for late follow-up examination, all were found to be in New York Heart Association class I or II. None had cyanosis or 
signs of congestive heart failure. All children underwent electrocardiographic evaluation before they were discharged and at every follow-up visit, and none had complete heart block. Seventeen children (85\%) had complete right bundle branch block and three $(15 \%)$ had incomplete right bundle branch block.

All children had complete Doppler echocardiographic evaluation before they were discharged, and 17 had late evaluation at our institution or in other hospitals. All had normal biventricular function and none had a residual ventricular septal defect. Mean right ventricular systolic pressure was $39.37 \pm 8.4$ $\mathrm{mm} \mathrm{Hg}$ (ranging from 26 to $65 \mathrm{~mm} \mathrm{Hg}$ ). The mean RVOT gradient was $10.67 \pm 10.8 \mathrm{~mm} \mathrm{Hg}$ (ranging from 0 to $35 \mathrm{~mm} \mathrm{Hg}$ ). Mild to mean pulmonary regurgitation was present in all patients (even those with monocusp pulmonary valve insertion), but in none was it graded as severe.

All children had late chest roentgenograms for evaluation of pulmonary vascular markings, cardiothoracic ratio, and occurrence of phrenic palsy. The pulmonary vascular markings were judged to be symmetric in $100 \%$ of patients, and the mean cardiothoracic ratio was $0.58 \pm 0.05$. Two children had phrenic palsy (one on the left side and the other on the right).

Up to 51 months after the operation, seven children had had catheterization (mean time $25.5 \pm$ 16.5 months) for evaluation of pulmonary arterial repair. None had residual stenosis. The mean pressure gradient between the left pulmonary artery and the pulmonary trunk was $12.8 \pm 7.8 \mathrm{~mm} \mathrm{Hg}$, and it was $8.4 \pm 6.5 \mathrm{~mm} \mathrm{Hg}$ between the right pulmonary artery and the pulmonary trunk. There was no aneurysm of the pedicled pericardial flap (Figs. 2 and 3).

Four other children underwent late chest MRI evaluation (Fig. 3), and none had residual stenosis. All had harmonious growth of their pulmonary arteries to a normal diameter.

Except for two patients lost to follow-up and one patient living in Algeria, all children operated on before March 1992 (14 patients) underwent either pulmonary angiography or chest MRI for evaluation of the pulmonary artery repair. All the results were analyzed and classified according to the criteria, described in Table IV.

\section{Discussion}

Pulmonary artery branch stenoses are widely known congenital anomalies or iatrogenic shunt- related complication in children with TOF. ${ }^{4,7,11-13}$ Many authors have reported hypoplastic or stenotic pulmonary artery branches to be a major obstacle to successful operative correction of TOF. ${ }^{14-16}$

Numerous techniques and materials have been used to repair such diseased pulmonary arteries, often with unsatisfactory late results, and presently no material has definitely been proved superior. ${ }^{5-7,16} \mathrm{An}$ explanation could be that the materials used to repair pulmonary arteries do not grow and may even shrink, resulting in progressive stenosis as the child grows. Autologous pericardial patches have been widely used for repair of the RVOT, but experimental studies showed that these patches are replaced by fibrous tissue and tend to become smaller with time. ${ }^{17,18}$

A recent study of Petit and associates ${ }^{3}$ concluded that polytetrafluoroethylene $(p<0.05)$ and pedicled pericardium $(p<0.005)$ were predictive factors for a good midterm surgical result when used for repair of hypoplastic or stenotic pulmonary arteries in children with TOF.

Pedicled pericardium as a vascular substitute was used by Senning ${ }^{19}$ in 1975 and by Tonkin and associates $^{20}$ in 1983, but Guyton and his coworkers ${ }^{8}$ were the first to demonstrate the growth potential of this material. These authors postulated that growth of this material was related to its native vascular and neural supply, and they concluded that this material could be used for enlargement of small pulmonary arteries or the RVOT in TOF or pulmonary atresia. Such success was achieved by Hvass and coworkers ${ }^{9}$ in 1987, who reported excellent results for three children operated on for TOF or pulmonary artery hypoplasia. Angiograms and repeated echocardiograms demonstrated uniform enlargement of the repaired pulmonary arteries over a 10 -month to 2 $1 / 2$-year follow-up period.

This result was observed in $100 \%$ of our patients: midterm angiograms or MRI and echocardiographic studies showed homogenous enlargement and no residual stenosis of the pulmonary arterial tree. One might think pedicled pericardium used for repair of the RVOT would dilate under the influence of abnormally high pressures remaining in the right ventricle, but all children had follow-up Doppler echocardiograms and in none did the pericardium dilate. Furthermore, no residual stenosis was observed in the pulmonary arteries. This may signify that pedicled pericardium did not shrink with time but rather grew in a parallel manner to the pulmo- 

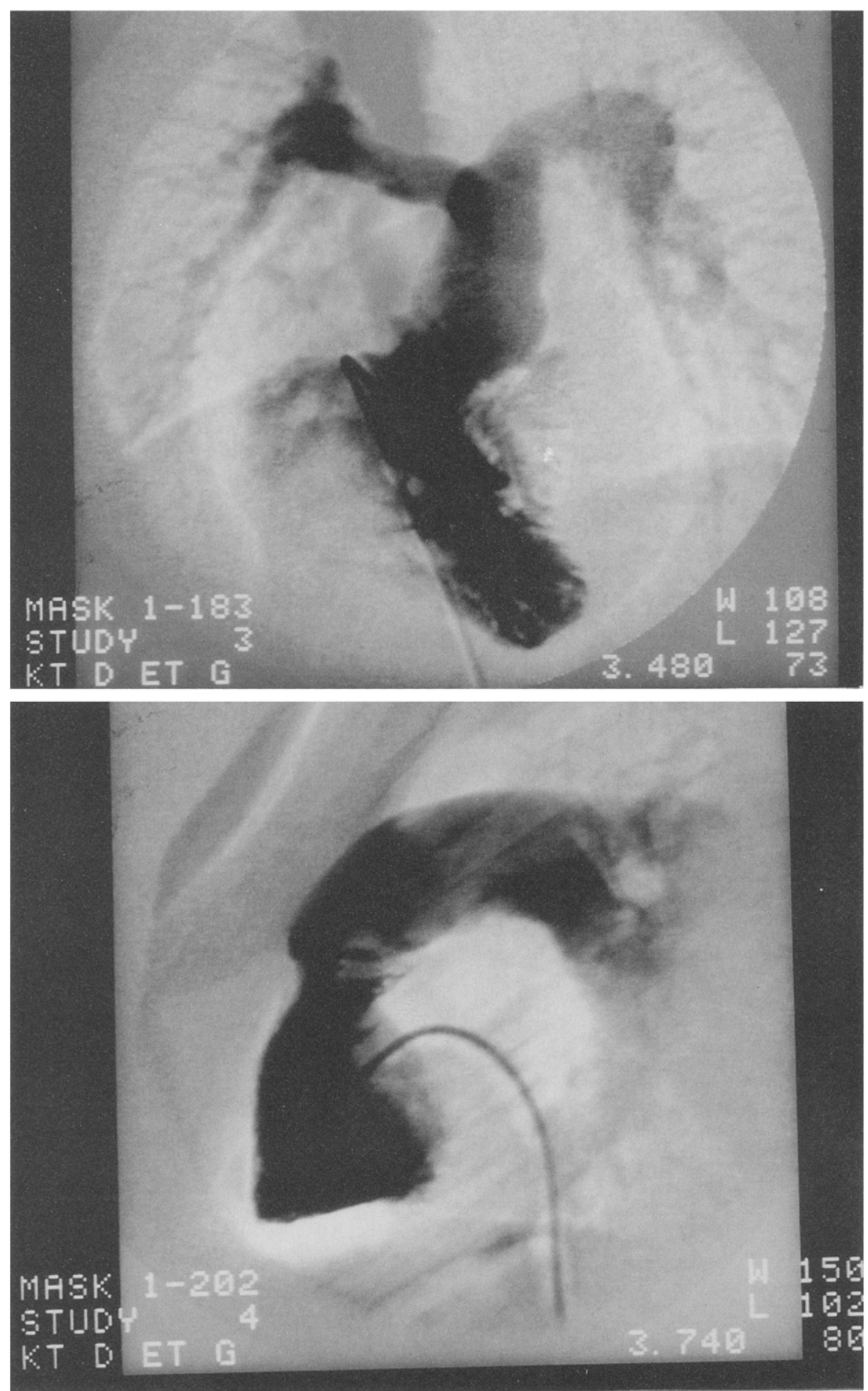

Fig. 2. Late postoperative right ventricular (top) and pulmonary (bottom) angiograms (anteroposterior and lateral views) in an 8-year-old boy operated on 4 years before for TOF and severe juxtaductal left pulmonary artery stenosis. The pulmonary trunk and the left pulmonary artery were enlarged by means of a large pedicled pericardial flap. There is no residual stenosis along the repaired site. 


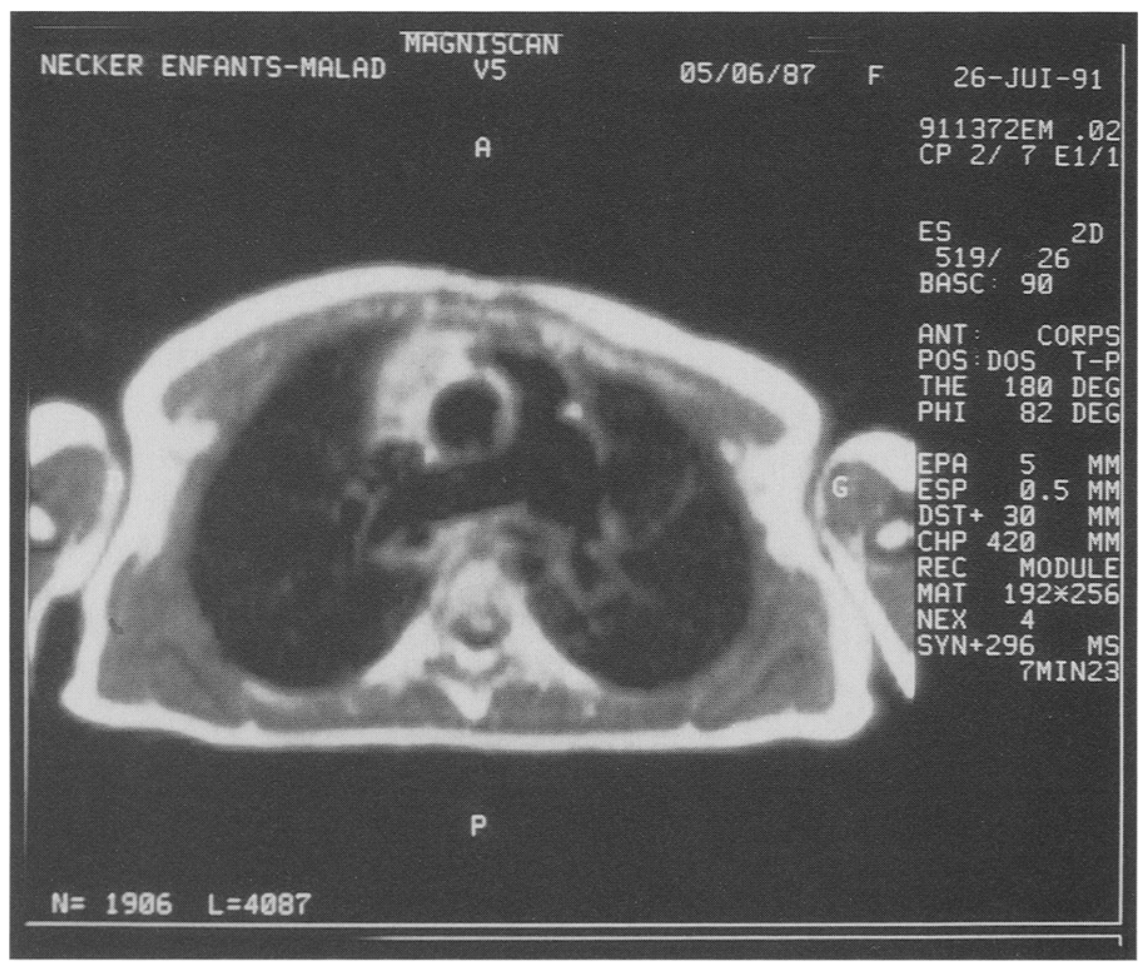

Fig. 3. MRI scan of the chest 32 months after the operation in a 4-year-old girl. Preoperatively, she had a tight stenosis at the origin of the left pulmonary artery, which was repaired by means of a pedicled pericardial flap. This transverse MRI scan through the pulmonary arteries shows no residual stenosis at the level of the left pulmonary artery and no distortion of the right pulmonary artery.

Table IV. Criteria for evaluation of the surgical repair and results of pulmonary artery repair with a pericardial flap

\begin{tabular}{|c|c|c|c|c|}
\hline Results & Doppler echocardiography & Angiography & $L P A$ & $R P A$ \\
\hline Good & Gradient $<25 \mathrm{~mm} \mathrm{Hg}$ & Ratio $>75 \%$ & $13 / 13$ & $1 / 1$ \\
\hline Fair & Gradient $<40 \mathrm{~mm} \mathrm{Hg}$ & Ratio $>50 \%$ to $\leq 75 \%$ & 0 & 0 \\
\hline \multirow[t]{2}{*}{ Poor } & Gradient $\geq 40 \mathrm{~mm} \mathrm{Hg}$ & Ratio $\leq 50 \%$ & 0 & 0 \\
\hline & $\begin{array}{l}\text { Pressure gradient between the repaired } \\
\text { pulmonary artery (LPA or RPA) and } \\
\text { the pulmonary trunk }\end{array}$ & $\begin{array}{l}\text { Ratio between the diameter of the narrowest } \\
\text { part of the repaired pulmonary artery and the } \\
\text { diameter of this artery at the prebranching point } \\
\text { (or at the contralateral prebranching point if the } \\
\text { considered artery was hypoplastic) }\end{array}$ & & \\
\hline
\end{tabular}

$L P A$, Left pulmonary artery; $R P A$, right pulmonary artery.

nary arteries. Although we were unable to demonstrate growth in the strict sense, our data support this idea. We previously used various materials for repair of pulmonary arteries, such as autologous pericardium or bovine pericardium, but we did not observe such good results. However, we agree that the older age of the majority of patients in this experience may constitute a selective bias regarding other experiences with younger children.

Kitagawa and associates ${ }^{21}$ recently reported the use of pedicled pericardium for construction of a new pulmonary trunk in a child with TOF and pulmonary atresia, hoping the growth potential of pedicled pericardium could avoid further reoperations to replace the pulmonary arterial trunk with an extracardiac conduit after growth of the child. We performed a similar operation in a 56-month-old girl with an anomalous left anterior descending coronary artery originating from the right coronary artery. Four years later, echocardiographic studies 
showed an excellent result with a pulmonary trunk and pulmonary arteries that have grown harmoniously. The growth potential is a fundamental property of pedicled pericardium, and we think that the viability is another interesting property of this material. This viability may be of great interest in the case of infection. We performed a pericardial flap for RVOT enlargement in an 8-year-old boy who was referred to our institution because of TOF and pulmonary endocarditis. The infection was controlled, and the echocardiographic result at 1 year is satisfactory. Insertion of a synthetic patch could have perpetuated the infectious process, and pedicled pericardium seemed to us an appropriate material in this situation.

Unfortunately, we observed two cases of postoperative phrenic nerve palsy (one left sided and one right sided) among the 20 patients. We postulate that these injuries were related to our use of crushed ice for myocardial protection. We do not believe these complications are due to the pericardial dissection associated with the pericardial harvest, because we always performed careful dissection, avoiding electrocauterization near the phrenic nerves. At the end of the operation, we always verified that there was no excessive tension on the pericardial flap. If tension was excessive, we generally lengthened the pericardial incision from the diaphragm to the pulmonary hilum along the left phrenic nerve to reduce excessive tension and to allow a better pericardial flap rotation.

All our anastomoses have been performed with 7-0 or 6-0 absorbable sutures for the pulmonary arteries and 6-0 or 5-0 nonabsorbable sutures for the infundibulum. We believe it is fundamental to obtain a tight suture line, because the sutured area may be difficult to reach if bleeding occurs. Biologic glue was widely used on the suture lines in the hope of reducing excessive bleeding. Only one of our patients had severe bleeding on a pulmonary branch anastomosis. This child was readmitted on an emergency basis to the operative room and we created a window in the pericardial flap to add some stitches. A pulmonary angiogram was performed 3 years later and showed no significant stenosis on the repaired pulmonary branch.

\section{Conclusion}

We report our 6-year experience with pedicled pericardial flaps used for repair of RVOT and pulmonary arteries in TOF. Our results are satisfactory, and we consider pedicled pericardium to be the material of choice for repair of hypoplastic or stenotic pulmonary arteries in children. However, our mean follow-up period is about 3 years, and longer-term evaluation is essential to assess the behavior of this material.

\section{REFERENCES}

1. Kirklin JW, Barratt-Boyes BG. Ventricular septal defect and pulmonary stenosis or atresia. In: Cardiac surgery. New York: John Wiley, 1986:699-781.

2. Blackstone EH, Kirklin JW, Bertranou EG, Labrosse CJ, Soto B. Preoperative prediction from cineangiograms of postrepair right ventricular pressure in tetralogy of Fallot. $\mathbf{J}$ Thorac Cardiovasc Surg 1979;78:542-52.

3. Petit A, d'Athis P, Baietto C, Kachaner J, Lusson JR, Worms AM. Results of surgical repair of branch pulmonary artery stenosis in tetralogy of Fallot (in French). Arch Mal Coeur 1992;85:533-9.

4. Hennein HA, Mosca RS, Urcelay G, Crowley DC, Bove EL. Intermediate results after complete repair of tetralogy of Fallot in neonates. J Thorac Cardiovasc Surg 1995;109:33244.

5. Aigueperse J, Lemoine G, Lecompte Y, et al. Stenosis of the bifurcation of the pulmonary trunk in radical cure of the tetralogy of Fallot (in French). Ann Chir 1983;37:506-10.

6. Lecompte Y, Tran Viet T, Leca F, et al. Stenosis of the proximal segment of the pulmonary arteries in the tetralogy of Fallot (in French). Ann Chir 1983;37:510-1.

7. Bical O, Tran Viet T, Leca F, et al. Tetralogy of Fallot and stenosis of the pulmonary arteries after palliative anastomosis (in French). Ann Chir 1983;37:513-6.

8. Guyton RA, Dorsey LM, Silberman MS, et al. The broadly based pericardial flap: a tissue for atrial wall replacement that grows. J Thorac Cardiovasc Surg 1984;87:619-25.

9. Hvass U, Khoury W, Pansard Y, Videcoq M. Repair of pulmonary artery branches with broadly based autologous pericardial flaps (letter). J Thorac Cardiovasc Surg 1988;95: 738.

10. Lev M, Rimoldi HJA, Rowlatt UF. The quantitative anatomy of cyanotic tetralogy of Fallot. Circulation 1964; 30:531-8.

11. Fellows KE, Smith J, Keane JF. Preoperative angiocardiography in infants with tetrad of Fallot. Am J Cardiol 1981; 47:1279-85.

12. Elzenga NJ, Suylen RJV, Frohn-Mulder I, Essed CE, Bos E, Quaegebeur JM. Juxtaductal pulmonary artery coarctation. J Thorac Cardiovasc Surg 1990;100:416-24.

13. Tamisier D, Vouhe PR, Vernant F, Leca F, Massot C, Neveux JY. Modified Blalock-Taussig shunts: results in infants less than 3 months of age. Ann Thorac Surg 1990;49: 797-801.

14. Kirklin JW, Blackstone EH, Kirklin JK, Pacifico AP, AramendiI J, Bargeron LM. Surgical results and protocols in the spectrum of tetralogy of Fallot. Ann Surg 1983;198: 251-65.

15. Kirklin JK, Kirklin JW, Blackstone EH, Milano A, Pacifico $\mathrm{AD}$. Effect of transannular patching on outcome after 
repair of tetralogy of Fallot. Ann Thorac Surg 1989;48:78391.

16. Seybold-Epting W, Chiarello L, Hallman FL, Cooley DA. Aneurysm of pericardial right ventricular outflow tract patches. Ann Thorac Surg 1977;24:237-40.

17. Egerton WS, Windsor MF. Assessment of autogenous and prosthetic materials in the right ventricular outflow tract. Aust N Z J Surg 1965;35:63-71.

18. Hjelms E, Pohlner P, Barratt-Boyes BG, Gavin JB. Study of autologous pericardial patch-grafts in the right ventricular outflow tracts in growing and adult dogs. J Thorac Cardiovasc Surg 1981;81:120-3.

19. Senning A. Correction of transposition of the great arteries. Ann Surg 1975;182:287-92.

20. Tonkin MD, Allen RG, Casini M, et al. Modified Shumacker repair of transposition of the great arteries. J Thorac Cardiovasc Surg 1983;85:306-12.

21. Kitagawa $\mathrm{T}$, Katoh I, Chikugo $\mathrm{F}$, et al. Technique for constructing the pulmonary trunk for tetralogy of Fallot with pulmonary atresia. Ann Thorac Surg 1995;59:1245-8. 